\title{
Approach to an Anemic Critically Ill Patient
}

\author{
Ashit Hegde \\ Indian Journal of Critical Care Medicine (2019): 10.5005/jp-journals-10071-23247
}

Anemia is almost inevitable in patients admitted to the ICU. Whereas nearly $50 \%$ of patients are anemic at the time of admission to the ICU (usually due to their chronic illnesses or due to blood loss), a vast majority of the remainder become anemic during their stay in the ICU. ${ }^{1}$ There are several reasons why patients in the ICU become anemic and often patients have anemia due to a combination of causes: ${ }^{2}$

- Bleeding: Many patients are admitted to the ICU because of bleeding from various sites due to trauma, surgery, coagulopathy, liver disease, etc. Patients admitted for other reasons may develop bleeding after admission. The gastrointestinal tract is the most common site for this bleeding though this may not be obvious in many cases. Coagulopathy, which is very common in ICU patients, for a variety of reasons, will certainly contribute to the bleeding. Nearly one third of the blood transfused in the ICU is for management of the bleeding patient.

- Phlebotomy: ${ }^{3}$ This is an under-recognized cause of anemia in the critically ill. In the average adult ICU patient, approximately $40-70 \mathrm{~mL}$ of blood is collected each day for investigations and only a fraction of this collected blood is actually processed. The sicker patients might have even more blood collected. It must also be remembered that only approximately $12.5 \mathrm{~mL}$ of blood is regenerated each day and this is not enough to compensate for the blood lost.

- Increased levels of Hepcidin: ${ }^{4,5}$ Hepcidin is produced by the liver and is the main controller of iron metabolism. The various cytokines that are released during a critical illness increase hepcidin levels. This increased level of hepcidin decreases the absorption of iron from the Gl tract and also traps the iron in its stores in the reticuloendothelial system (RES) and makes less iron available to the bone marrow. This cause of anemia is similar to the anemia of chronic infection/inflammation (Fig. 1).

- Erythropoietin: Erythropoietin levels are significantly reduced in the critically ill patient and to compound matters, the bone marrow response to erythropoietin is also blunted. RBC production is therefore suppressed. ${ }^{6}$

- Decreased RBC life span: The life span of RBCs is reduced in critically ill patients probably due to the various cytokines release. $^{7}$

- Nutritional deficiency: Iron, $\mathrm{B}_{12}$ or folate deficiency is fairly common in our country and these deficiencies may get aggravated in the ICU because of inadequate nutritional support and the increased demands of these substrates in critical illness. ${ }^{8}$

- Drug-induced: Drugs may cause anemia either by causing an immune hemolysis or by bone marrow suppression. While drug reactions may not be one of the more common causes of anemia , this cause should be considered when there is no other explanation for declining hemoglobin levels. ${ }^{9}$
Department of Critical Care and Medicine, PD Hinduja National Hospital and Medical Research Centre, Mumbai, Maharashtra, India

Corresponding Author: Ashit Hegde, Department of Critical Care and Medicine, PD Hinduja National Hospital and Medical Research Centre, Mumbai, Maharashtra, India, e-mail: ahegde1957@gmail.com

How to cite this article: Hegde A. Approach to an Anemic Critically III Patient. Indian J Crit Care Med 2019;23(Suppl 3):S178-S180.

Source of support: Nil

Conflict of interest: None

\section{Diagnosing the Cause of Anemia in the Critically Ill}

While anemia is probably inevitable in most ICU patients, a good history taking, a proper clinical examination and appropriate lab investigations might help detect some treatable causes of anemia.

\section{History and Clinical Examination}

A history of recent trauma, surgery, or overt bleeding from any site must be sought. The patient's drug history especially a history of consumption of NSAIDs, anticoagulants, antiplatelet agents, bone marrow suppressants and drugs that may potentially cause a hemolytic anemia (piperacillin, primaquine, ceftriaxone, etc.) A history of any chronic ailment - renal, liver, thyroid, malignancy, rheumatologic disease, might explain some of the patient's anemia.

The patient must be carefully examined for any evidence of overt bleeding (especially puncture sites, surgical wounds), icterus (suggesting hemolysis or chronic liver disease) purpura or ecchymosis (suggesting a coagulopathy).

\section{INVESTIGATIONS}

Recheck the hemoglobin level to rule out a lab error (not uncommon), check renal and liver function. Stools must be examined for occult blood. A sonography might be necessary in patients who have suffered trauma or have undergone recent surgery or in coagulopathic patients with no other obvious source of bleeding. A high LDH and reticulocyte count and /or positive Coombs test might suggest hemolysis.

Iron-binding studies will be usually suggestive of an anemia of chronic disease but might be difficult to interpret in the critically ill because ferritin levels and iron-binding capacity are affected by the critical illness itself. Serum $B_{12}$ and folate levels may be checked [especially if mean corpuscular volume (MCV) is on the higher side]. In any case, in patients with a microcytic anemia, all efforts to locate the source of occult bleeding (usually the GI tract) must be made. An ultrasound examination might be necessary in patients with recent trauma, surgery or an unexplained reason for anemia. The

(0) The Author(s). 2019 Open Access This article is distributed under the terms of the Creative Commons Attribution 4.0 International License (https://creativecommons. org/licenses/by-nc/4.0/), which permits unrestricted use, distribution, and non-commercial reproduction in any medium, provided you give appropriate credit to the original author(s) and the source, provide a link to the Creative Commons license, and indicate if changes were made. The Creative Commons Public Domain Dedication waiver (http://creativecommons.org/publicdomain/zero/1.0/) applies to the data made available in this article, unless otherwise stated. 


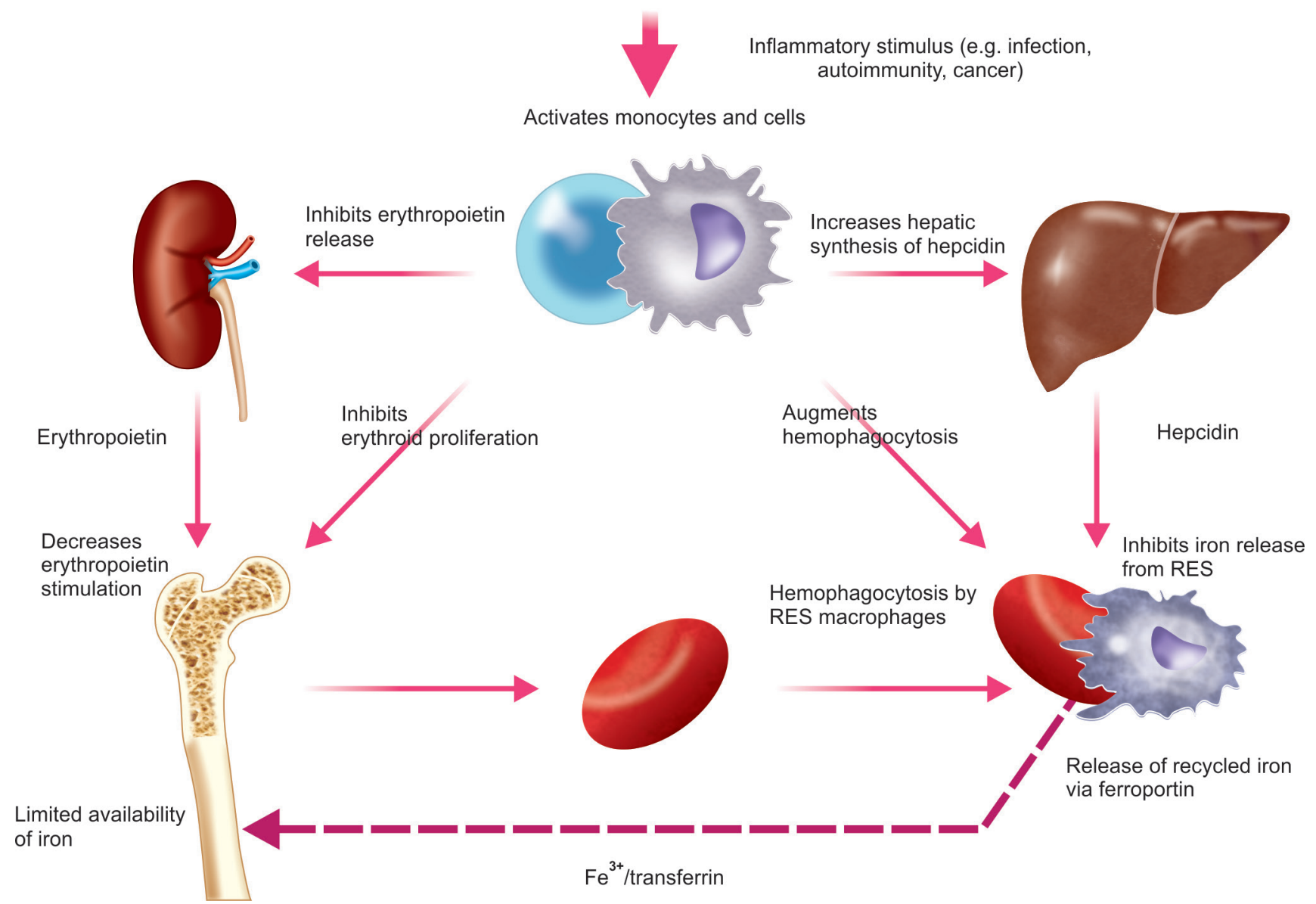

Fig. 1: Anemia of chronic disease. These mechanisms are similar in the critically ill patients. The anemia is related to high hepcidin and low erythropoietin levels. (http://www.medicoaid.com/qod-556-anemia-of-chronic-disease/last accessed on 8th September 2019)

peripheral smear must be examined for clues suggesting hemolysis or a microangiopathic hemolytic anemia.

\section{Management of Anemia in the ICU}

Anemia might have adverse effects in the critically ill patient, especially in those with limited cardiorespiratory reserve and in patients with neurologic problems. There is however no strong evidence that treatment of anemia improves outcomes. Packed cell transfusions are often prescribed for the management of anemia. Transfusions however also have side effects viz TRALI, TACO, immune suppression, etc. The potential risks of transfusions must be weighed against the probable benefits. ${ }^{10}$ After the publication of the landmark TRICC trial, there has been a trend toward restrictive transfusion policies in most ICUs. ${ }^{11}$ The triggers for transfusion, however, vary from patient to patient and will be dealt with in a subsequent chapter in this issue. A few strategies might help prevent/decrease the incidence of anemia and the need for transfusions.

- Attempts must be made to limit the amount of blood drawn for investigations. The use of closed-circuit systems for blood collection, point-of-care testing and the use of small volume (pediatric) phlebotomy tubes might limit the amount of blood wasted.

- Stress ulcer prophylaxis should be initiated when indicated.

- Early nutritional support with supplements of vitamins and trace elements might prevent the nutritional causes of anemia.
- Iron therapy: In ICU patients, Iron is not well absorbed from the gut, nor is it released efficiently from its stores. Oral Iron will probably not be useful. Theoretically IV iron might help overcome this functional iron deficiency. Iron supplementation however might increase the risk of bacterial infections. ${ }^{12}$

- Pieracci et al. conducted a multicenter randomized trial of IV iron supplementation for anemia of traumatic critical illness, in 2014. The study revealed that though IV iron increased serum ferritin levels significantly, there was no impact on hemoglobin levels or the need for transfusions. ${ }^{13}$

- The recently conducted IRONMAN study compared IV iron to placebo in the treatment of anemic patients admitted to the ICU. The study concluded that IV Iron therapy did not significantly decrease the need for RBC transfusion. However, patients who received IV iron had a much higher hemoglobin level at discharge from the ICU. All other outcomes were similar in both groups. ${ }^{14}$ On the basis of these studies, routine supplementation of IV iron cannot be recommended as yet for anemic ICU patients.

- $\quad$ Erythropoiesis stimulating agents (ESA): Critically ill patients are resistant to the effects of erythropoietin. Studies of high dose ESAs in the management of anemia in ICU have been disappointing. ${ }^{15}$ The increase in hemoglobin levels were marginal; there was no improvement in any other outcomes and there was a small increase in the incidence of thrombotic events. For now ESAs can only be recommended for patients 
in ICU suffering from chronic kidney disease or for patients suffering from trauma.

\section{SUMMARY}

Anemia is very common in the critically ill patient and the cause is usually multifactorial. Though anemia is associated with worse outcomes, correction of this anemia may not necessarily improve outcomes. The evidence for alternatives to transfusion (IV iron, ESA) has been disappointing. RBC transfusions should be used judiciously and all attempts must be made to prevent wastage of blood.

\section{References}

1. Vincent JL, Baron JF, Reinhart K, Gattinoni L, Thijs L, Webb A, et al. ABC (Anemia and Blood Transfusion in Critical Care) Investigators. Anemia and blood transfusion in critically ill patients. JAMA 2002;288:14991507.

2. Hayden SJ, Albert TJ, Watkins TR, Swenson ER. Anemia in critical illness: insights into etiology, consequences, and management. Am J Respir Crit Care Med 2012;185:1049-1057.

3. Chant C, Wilson G, Friedrich JO. Anemia, transfusion, and phlebotomy practices in critically ill patients with prolonged ICU length of stay: a cohort study. Crit Care 2006;10:R140.

4. Sihler KC, Raghavendran K, Westerman M, Ye W, Napolitano LM. Hepcidin in trauma: linking injury, inflammation, and anemia. J Trauma 2010;69:831-837.

5. Girelli D, Nemeth E, Swinkels DW. Hepcidin in the diagnosis of iron disorders. Blood 2016;127:2809-2813.

6. Jelkmann I, Jelkmann W. Impact of Erythropoietin on Intensive Care Unit Patients. Transfus Med Hemother. 2013;40:310-318.
7. Von Ahsen N, Muller C, Serke S, Frei U, Eckardt KU. Important role of nondiagnostic blood loss and blunted erythropoietic response in the anemia of medical intensive care patients, Crit Care Med 1999;27:2630-2639.

8. Rodriguez RM, Corwin HL, Gettinger A, Corwin MJ, Gubler D, Pearl RG. Nutritional deficiencies and blunted erythropoietin response as causes of the anemia of critical illness. J Crit Care 2001;16:36-41.

9. Garratty G. Immune hemolytic anemia caused by drugs. Expert Opin Drug Saf. 2012;11:635-642.

10. Vincent JL, Sakr Y, Sprung C, Harboe S, Damas P. Are blood transfusion associated with greater mortality rates? Results of the sepsis occurrence in acutely ill patients (SOAP) study. Anesthesiology 2008;108:31-39.

11. Hébert PC, Wells G, Blajchman MA, Marshall J, Martin C, Pagliarello G, et al. A multicenter, randomized, controlled clinical trial of transfusion requirements in critical care. Transfusion Requirements in Critical Care investigators, Canadian Critical Care Trials Group. N Engl J Med 1999;340:409-417.

12. Pieracci FM, Henderson P, Rodney JR, Holena DN, Genisca A, Ip I, et al. Randomized, double-blind, placebo controlled trial of effects of enteral iron supplementation on anemia and risk of infection during surgical critical illness. Surg Infect (Larchmt) 2009;10:9-19.

13. Pieracci FM, Stovall RT, Jaouen B, Rodil M, Cappa A, Burlew CC, et al. A multicenter, randomized clinical trial of IV iron supplementation for anemia of traumatic critical illness. Crit Care Med 2014;42:2048-2057.

14. IRONMAN Investigators, Litton E, Baker S, Erber WN, Farmer S, Ferrier J, et al. Australian and New Zealand Intensive Care Society Clinical Trials Group. Intravenous iron or placebo for anaemia in intensive care: the IRONMAN multicentre randomized blinded trial: a randomized trial of IV iron in critical illness. Intensive Care Med 2016;42:1715-1722.

15. Corwin HL, Gettinger A, Rodriguez RM, Pearl RG, Gubler KD, Enny C, et al. Efficacy of recombinant human erythropoietin in the critically ill patient: a randomized, double-blind, placebo- controlled trial. Crit Care Med 1999;27:2346-2350. 